\title{
The interplay between reactive oxygen species and antioxidants in cancer progression and therapy: a narrative review
}

\author{
Osama Hussein Bekhet ${ }^{1}$, Mohamed Elsayed Eid ${ }^{2}$ \\ ${ }^{1}$ Pole of Endocrinology, Diabetes and Nutrition, Catholic University of Louvain, Woluwe-Saint-Lambert, Belgium; ${ }^{2}$ Laboratory of Natural Products \\ Chemistry, Mediterranean Agronomic Institute of Chania, Crete, Greece \\ Contributions: (I) Conception and design: OH Bekhet; (II) Administrative support: None; (III) Provision of study materials or patients: None; (IV) \\ Collection and assembly of data: None; (V) Data analysis and interpretation: None; (VI) Manuscript writing: Both authors; (VII) Final approval of \\ manuscript: Both authors. \\ Correspondence to: Osama Hussein Bekhet. Pole of Endocrinology, Diabetes and Nutrition, Catholic University of Louvain, Woluwe-Saint-Lambert, \\ Belgium. Email: osama.bekhet@uclouvain.be.
}

Objective: To unveil the role of reactive oxygen species (ROS) and antioxidants in signaling and involvement in cancer progression and therapy.

Background: Cancer is considered one of the main causes of mortality in developed countries and expected to be more in developing countries as well. Although some cancers may develop at young age, yet almost all types of cancers are an accumulation of genetic and epigenetic cell damages. Cancer is considered a diverse collection of diseases on a cellular level rather than a single disease; and each disease has a different cause as well. ROS have been seen as harmful toxic molecules; however, they are recognized for cellular signaling capabilities. Elevated levels of ROS have protumorigenic activities; they induce cancer cell proliferation, and adaptation to hypoxia in addition to other effects like DNA damage and genetic instability. They are produced excessively by cancer cells to hyperactivate cellular transformation meanwhile increasing antioxidant capacity to avoid cell death.

Methods: We discussed peer reviewed published research work from 1987 to 2021. In this paper, we review the role of antioxidants as defensive barrier against excessive ROS levels for maintaining oxidationreduction (redox) balance; however, antioxidant can also strive in tumor cells with their scavenging capacities and maintain protumorigenic signaling and resist the cancer cell oxidative stress and apoptosis. High doses of antioxidant compounds could be toxic to cells as they are capable of reacting with the physiological concentrations of ROS present for normal cellular processes and signaling.

Conclusions: Maintaining cellular redox homeostasis is vital for healthy biological system. Therefore, therapeutic modalities for cancer including antioxidants and ROS management should be used at certain doses to target specific redox pathways involved in cancer progression without disrupting the overall redox balance in normal cells.

Keywords: Cancer; reactive oxygen species (ROS); antioxidants; signaling; oxidative stress

Submitted Apr 12, 2021. Accepted for publication Jul 30, 2021.

doi: 10.21037/tcr-21-629

View this article at: https://dx.doi.org/10.21037/tcr-21-629

\section{Introduction}

Reactive oxygen species (ROS) are molecules containing reactive oxygen that participate in cellular electron transfer (1). ROS were first studied for tumorigenesis promoting activity in the mid-90s $(2,3)$; however, their cellular homeostasis is essential for normal cell survival and proper cell signaling. Low ROS levels can activate signaling pathways in a regulatory manner that is essential for metabolic adaptation, differentiation and cellular 


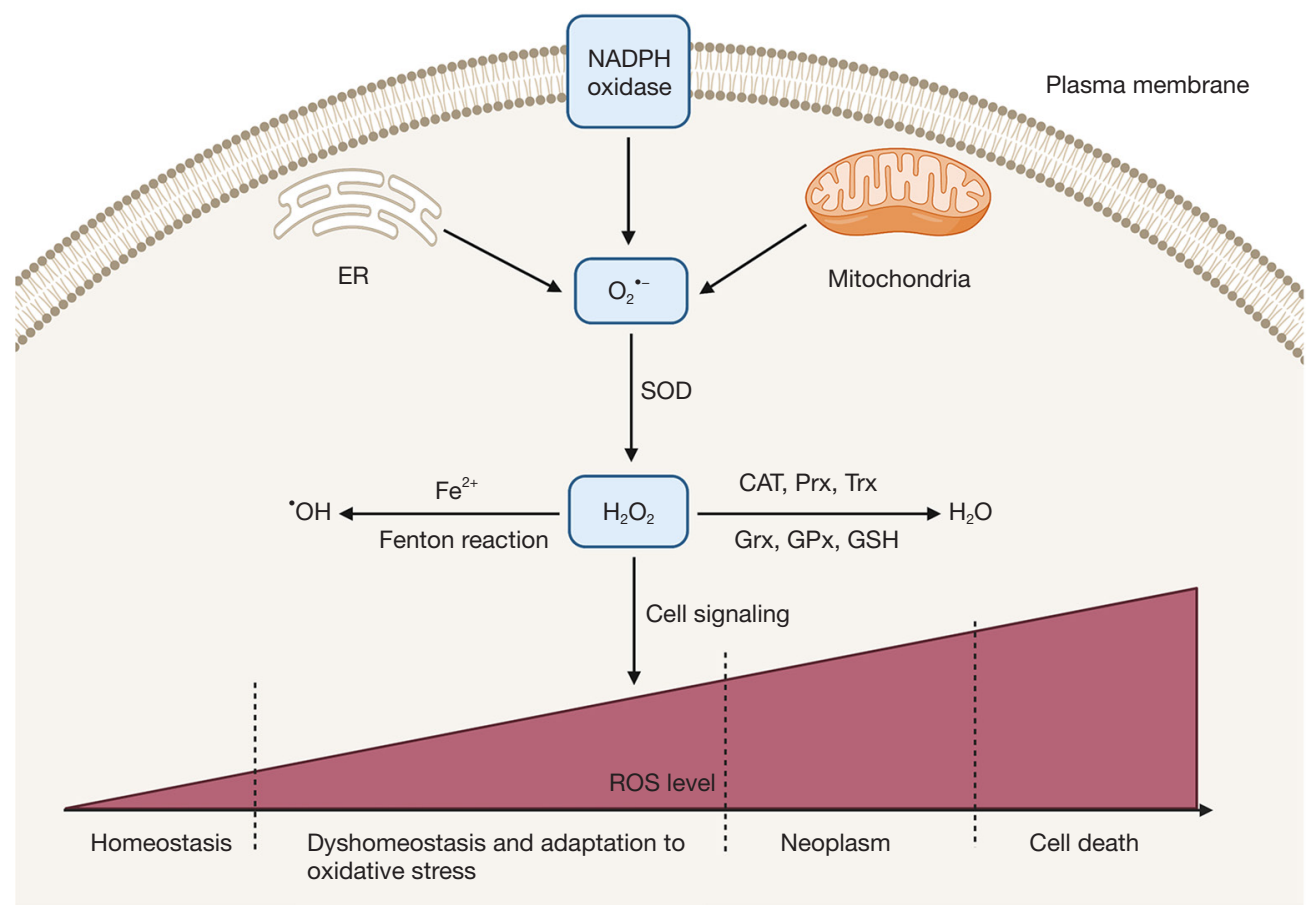

Figure 1 The vital roles of reactive oxygen species (ROS) and antioxidants in cancer progression and treatment. Redox homeostasis is a balance of ROS generation and elimination. Mitochondria, NADPH oxidase, and endoplasmic reticulum (ER) are the three main sources of ROS generation. Superoxide anion radical $\left(\mathrm{O}_{2}{ }^{-}{ }^{-}\right)$is the principal form of ROS and can be rapidly converted into hydrogen peroxide $\left(\mathrm{H}_{2} \mathrm{O}_{2}\right)$ by superoxide dismutase (SOD). $\mathrm{H}_{2} \mathrm{O}_{2}$ can be converted to hydroxyl radical $\left({ }^{\circ} \mathrm{OH}\right)$ in the presence of $\mathrm{Fe}^{2+}$ or $\mathrm{Cu}^{2+}$ ions via Fenton reaction or be catalyzed to $\mathrm{H}_{2} \mathrm{O}$ by CAT (catalase), Prx (peroxiredoxins), Trx (thioredoxins; Grx (glutaredoxins), GPx (glutathione peroxidases), and GSH (glutathione). The concentration of ROS determines the cell fate: low levels of ROS are necessary for cell signaling and homeostasis; intermediate levels of ROS result in loss of cell homeostasis and increased adaptation to oxidative stress, and subsequent transformation to neoplasm; while a severe and prolonged increase of ROS leads to cell death. The figure was adapted from Barbara Marengo et al. 2016 (5) and created using BioRender (https://biorender.com, accessed on 17 July 2021).

proliferation (4) as presented in Figure 1 (5).

ROS include hydrogen peroxide $\left(\mathrm{H}_{2} \mathrm{O}_{2}\right)$, superoxide anion radical $\left(\mathrm{O}_{2}{ }^{-}\right)$, and the hydroxyl radical $\left({ }^{\circ} \mathrm{OH}\right)$. These species have been suggested to be solely toxic and pathological molecules in the past years (6). However, it has been extensively studied for their control over various physiological reactions, including cell proliferation and differentiation, signaling, and adjustment to hypoxia $(7,8)$. ROS have a critical role in both cell mitochondria-tonucleus and membrane-to nucleus signaling pathways, regulating biochemical effectors, and also contribute to growth factor signal transduction $(9,10)$.

Up-regulated ROS levels and down-regulated cellular antioxidant enzymes lead to different malignancies through different molecular factors like nuclear factor kappa B (NF$\kappa \mathrm{B})$ and nuclear factor (erythroid-derived 2)-like-2 factor
(NRF2) (11). ROS cause DNA damage via nucleobases oxidation such as guanine. Since oxidized pair is subjected to repair, it can lead to an error that causes mutagenesis. ROS have multiple sources among which are physical stressors like extensive exercise, aerobic and anaerobic exercise and radiation. Physical stress is found to produce oxidative stress and production of $\mathrm{O}_{2}{ }^{--}$from mono-electric reduction of oxygen, which is considered as prototype for other ROS like $\mathrm{H}_{2} \mathrm{O}_{2},{ }^{\circ} \mathrm{OH}$ and $\mathrm{ROO}^{\circ}$ (12), while radiation is among the most recognized sources for ROS and hence highly correlated with initiation of cancer (13).

The cellular main redox couples are: cysteine (Cys)/ cystine (CySS), GSH/glutathione disulfide (GSSG), NADH/NAD ${ }^{+}, \mathrm{NADPH} \mathrm{NADP}^{+}$, peroxiredoxin (Prx)sulfiredoxin (Srx), and thioredoxin ( $\operatorname{Trx}$ )/thioredoxin disulfide (TrxSS). These enzymes work with thiol redox to 
control ROS levels (14). On the other hand, antioxidants were widely believed as protective agents against cancer as they have the ability to neutralize ROS and other free radicals causing DNA damage and leading to cancer, however many clinical trials failed to find an evident beneficial effect. Several epidemiological studies also show an inverse correlation between cancer and antioxidant-rich diets (15). For instance, total antioxidant capacity (TAC), measured through ferric-reducing ability of plasma score, was investigated in a study on total 393 pancreatic cancer patients and 353 pancreatic cancer-related deaths which concluded that lower TAC leads to higher incidence of pancreatic cancer (16).

In this review, we discuss the role of different ROS in cancer progression as well as their signaling role; and different antioxidants either exogenous or endogenous and their role in progression of different tumors. We present the following article in accordance with the Narrative Review reporting checklist (available at https://dx.doi.org/10.21037/ tcr-21-629).

\section{ROS acting as protumorigenic}

Oxidative stress as one of the most leading causes of toxicity, is attributed to ROS interactions with cellular macromolecules like DNA, and proteins, which interfere with cellular pathways signaling molecules such as protein kinases, and transduction mechanisms (17). ROS are mainly categorized into $\mathrm{O}_{2}{ }^{-}, \mathrm{H}_{2} \mathrm{O}_{2},{ }^{\circ} \mathrm{OH}$, and lipid peroxides. ROS are continually produced or in contact with cellular components, since they are formed as byproducts of oxidative phosphorylation (OXPHOS), or mitochondrial electron transport in aerobic respiration and they are kept by enzymatic antioxidants into homeostatic state $(18,19)$.

Elevated levels of ROS can occur by either ROS increased production or decreased elimination $(20,21)$. Whilst ROS levels are excessive, $\mathrm{H}_{2} \mathrm{O}_{2}$ can easily diffuse away from their site of production, resulting in oxidative damage and cellular death. Therefore, ROS action as signaling molecules or pathological agents mainly relies upon the type of ROS, their concentration, and the concentration of antioxidants (22).

$\mathrm{H}_{2} \mathrm{O}_{2}$ is the most reported signaling molecule $(23,24)$. $\mathrm{H}_{2} \mathrm{O}_{2}$ is a product of two electron reduction of $\mathrm{O}_{2}$. It is produced by at least thirty $\mathrm{H}_{2} \mathrm{O}_{2}$ generating enzymes like superoxide dismutase (SOD), xanthine oxidase and NADPH oxidase (NOX) (25). Due to its physiochemical properties, $\mathrm{H}_{2} \mathrm{O}_{2}$ molecules are capable of carrying redox signal from its site of generation to their target sites. The mechanism by which $\mathrm{H}_{2} \mathrm{O}_{2}$ contributes in cellular signaling is the oxidation of cysteine residues to maintain protein function (26).

ROS signaling molecules are either formed in mitochondria or via membrane bound NOXs, while we have 10 sites for $\mathrm{O}_{2}{ }^{--}$production in mitochondria, the $\mathrm{O}_{2}{ }^{-}$ molecules contributing to redox signaling are the ones derived from mitochondrial complexes I, II, and III, while $\mathrm{H}_{2} \mathrm{O}_{2}$ is derived from the action of SOD 1, 2 and 3 (SOD) on $\mathrm{O}_{2}{ }^{-}-(27,28)$. As $\mathrm{O}_{2}{ }^{-}$is released in the mitochondria, it is readily converted by SOD2 into $\mathrm{H}_{2} \mathrm{O}_{2}$ (29). SOD1 acts to detoxify $\mathrm{O}_{2}{ }^{--}$within the mitochondrial intermembrane space producing freely diffusible $\mathrm{H}_{2} \mathrm{O}_{2}$.

NOXs have a role in both ROS generation and detoxification, as membrane bound NOX is one of the major oxidants in cancer. Both NADPH 1-5 and Dual Oxidases 1, 2 (DUOX 1,2) contribute to $\mathrm{H}_{2} \mathrm{O}_{2}$ and $\mathrm{O}_{2}{ }^{-}$production by either one electron or two electron reduction of oxygen (30). Although NOX is localized mainly in plasma membrane, it can also be found in nucleus membrane, mitochondrial membrane, and membrane of endoplasmic reticulum. Additionally, $\mathrm{O}_{2}{ }^{-}$has shown to have a role in redox signaling and the initiation of cell death (31). ${ }^{\circ} \mathrm{OH}$ is formed when $\mathrm{H}_{2} \mathrm{O}_{2}$ undergoes Fenton chemistry with ferrous or cuprous ions, leading to damage of lipids, proteins, and DNA. In case of ROS abundance, metastasis of many types of cancers including breast, prostate, and ovarian cancer is correlated with their cellular redox state (32), as redox imbalance will lead to a mitogen activated protein kinases (MAPK) signaling cascade which is involved in tumor cell migration (33). The phosphatidylinositol 3-kinase and protein kinase B (PI3K/ Akt) survival pathway which are activated in most cancers, are found to be induced by ROS (34). Moreover, the oncogenic activation of Akt increases ROS production which promotes cancer cell proliferation (35).

In another study, Ras oncogenic mutations were found to increase NOX4 mediated ROS generation which enhances tumor proliferation (36). NOX4 also contributes to certain types of malignancies, such as renal cancer. NOX4 was found in an ATP bound inactive form in inner mitochondrial membrane. When activated after ATP redistribution and metabolic reprogramming, it gives rise to anticancer drug resistance. Similarly, in ovarian and breast cancer, with overexpression of $\mathrm{NOX} 4$, and $\mathrm{H}_{2} \mathrm{O}_{2}$ dependent nonsense mutations, resulting in the tumor promoting behavior of NOX4 as well as anticancer therapy resistance (37). Another study has shown that inhibition of NOX generated ROS will lead to a decreased potential 
for tumorigenesis in diverse cancer types, e.g., inhibited NOX generated ROS in pancreatic cancer treated with flavoprotein inhibitor diphenylene iodonium (DPI), resulted in apoptosis through AKT/ apoptosis signal regulating kinase 1 (ASK1) pathway (38).

When a proliferative tumor outgrows their main blood supply, regions of the solid tumor enter a state of hypoxia and low glucose supply implying more ROS generation. Cancer cell will then activate metabolic pathways which will stabilize bypoxia-inducible factors (HIFs), activating AMP-activated protein kinase (AMPK) to enhance $\mathrm{NADPH}$ production in an attempt to maintain redox balance (39). Tumor cells adapt to hypoxia by activating glucose metabolism; as tumor cells use glycolysis whether there's oxygen deficiency or not, this results into a more aggressive phenotypes, in a phenomenon known as Warburg effect (40). Glycolysis plays an essential role in redox homeostasis through transportation of metabolic intermediates such as pentose phosphate pathway (PPP) which activates overproduction of reducing agents like glutaminolysis-generated GSH and NADPH, thus tumor cells adapt to glucose deprivation by increasing glycolysis to compensate the excessive production of ROS and inhibit glucose-hydroperoxide cell death (41). Moreover, during hypoxia, the HIF- $\alpha$ protein and HIF- $\beta$ protein subunits are dimerized, translocated to the nucleus and incite the expression of proangiogenic genes like vascular endothelial growth factors and other genes for cancer cell survival and metastasis $(42,43)$. HIF- $\alpha$ protein stabilization through ROS dependent mechanism is found to promote tumorigenesis of certain cancer cells $(43,44)$.

It is also evident that the ratio between $\mathrm{O}_{2}{ }^{-}$and $\mathrm{H}_{2} \mathrm{O}_{2}$ determines whether it will induce cell survival or cell death. The ratio predominates in favor of increased $\mathrm{O}_{2}{ }^{--}$ as in tumor cells where antioxidants are ineffective; this condition will promote cell survival by means like activating $\mathrm{PI} 3 \mathrm{~K} /$ Akt H+ efflux pumps which will eventually result in cancer proliferation or progression. Whereas the ratio is in favor of $\mathrm{H}_{2} \mathrm{O}_{2}$, this induces cell death signaling by cytosolic acidification (activated caspases), mitochondrial death factors recruitment, and exerting inhibitory effect on intracellular $\mathrm{O}_{2}{ }^{--}$production and accumulation.

Since ROS change cellular processes as a result of changing protein function, the disulfide redox state will then be changed leading to cancer, by the action of NOX or xanthine oxidase (45). ROS can also initiate pro-oncogenic signaling pathways, e.g., KRAS transformation which is found in numerous cancerous cells and contribute to cancer cells intrusion and relocation. For instance, mutations in Kelch-like ECH-associated protein 1 (KEAP1), NRF2 or the KRAS oncogenes result in enhanced ROS scavenging through NRF2-mediated gene expression in cancer cells to maintain ROS homeostasis and prevent ROS mediated activation of death-inducing $\mathrm{JNK} / \mathrm{p} 38$, causing irreversible oxidative damage to cancer cell. Mutations in Keap1 and NRF2 have been associated with many cancers including colon, breast, gastric and liver cancer, thus NRF2 is an important factor for cancer cell tumorigenesis and proliferation $(43,46)$.

It is yet unclear how proteins are specifically targeted and efficiently oxidized by $\mathrm{H}_{2} \mathrm{O}_{2}$, given the extensive and multicompartmental cellular antioxidant system, however a suggested mechanism for targeted protein oxidation by $\mathrm{H}_{2} \mathrm{O}_{2}$ is due to ROS scavenging enzymes that can transduce the $\mathrm{H}_{2} \mathrm{O}_{2}$ signals (47). The impact of ROS in relation to protein oxidation, as mild oxidative function in protein signaling, is a reversible process (disulfide, sulfenic acid and sulfinic acid formation), while the terminal oxidation into sulfonic acid leads to a complete loss of protein function (48). Higher ROS levels may cause post-translational modification of histidine, methionine, and cysteine. The widely known mechanism for $\mathrm{H}_{2} \mathrm{O}_{2}$ to achieve their cellular regulatory function is by redox-balance of cysteine residue by redox-sensitive proteins. Cysteine is oxidized by $\mathrm{H}_{2} \mathrm{O}_{2}$ into cysteine sulfenic acid (Cys-SOH) or disulfide (cystine). With exposure to ROS, thiol group of cysteine residues in proteins like transcriptase, phosphatase and kinase is oxidized (49-52).

The p53 tumor suppressor gene is found to play a regulatory role in ROS accumulation by inducing the expression of several antioxidant genes like SOD2, glutathione peroxidase 1 (GPX1), and catalase (CAT), thus when $\mathrm{p} 53$ is exposed to mutation or loss of function, ROS accumulation is observed in more than $50 \%$ of human cancers $(53,54)$. Mutations of $\mathrm{p} 53$ were found to enhance angiogenic response in ROS mediated activation of vascular endothelial growth factor A (VEGF-A) and HiF-1 in HCT116 human colorectal carcinoma cells (55). A recent study on liver cancer cells, treated with rhein, the main active compound of rhubarb medicinal plant, has concluded cell cycle arrest and apoptotic pathway via excessive ROS generation which in time activates c-Jun $\mathrm{N}$-terminal kinases (JNK/Jun/caspase-3) signaling pathway in HepG2 and Huh7 cells (56).

TP53-induced glycolysis and apoptosis regulator (TIGAR) has been found to promote tumor chemotherapy 
resistance, as it has been overly expressed in cancer and oncotherapy as in tamoxifen resistance in MCF-7, and dasatinib resistance in chronic lymphocytic leukemia, additionally it decreases ROS in tumor cell eventually promoting its growth (57). The 5-fluorouracil (5-FU) as an antimetabolite drug, generates mitochondrial ROS by $\mathrm{p} 53$ dependent pathway (58). It was also found that $\mathrm{p} 53-$ mediated ferroptosis, a nonapoptotic form of cell death, leads to p53-dependent inhibition of the cysteine-glutamate antiporter $\mathrm{xCT}$ (SLC7A11), which subsequently elevates ROS levels (59).

\section{Antioxidants acting as protumorigenic}

Cancer patients have been taking antioxidants as an alternative medicine in form of nutritional supplement, either after or during conventional cancer therapy, often at higher doses than recommended dietary allowance (RDA), in an attempt to improve the quality of life for cancer patients $(60,61)$; yet there is no sufficient evidence that antioxidants have such beneficial effects. On the other hand, some studies suggested that using antioxidant with the conventional concentrations may not be sufficient to counter the high yield of reactive oxygen metabolite produced, and may then promote cell proliferation and malignancy progression (62). Other in vitro and in vivo data concluded that antioxidants selectively inhibiting tumor cell progression, may alter cellular redox balanced status, leading to an enhanced cytotoxic effect of the therapy (63-66).

The suggested rationale for using antioxidant supplementation during chemotherapy, is to compensate the total antioxidant decline (measured by total radical antioxidant parameter/serum micronutrients) due to depletion of antioxidants after treatment, as some studies tried to investigate the effect of a single or a combination of antioxidants with chemotherapy; yet the evidence for such depletion isn't conclusive (67). The antioxidant system in our bodies have two main groups, endogenous antioxidants (enzymatic o non enzymatic) e.g., glutathione (GSH), glutathione peroxidase (GPx), CAT and SOD among many others, while exogenous antioxidants such as vitamins ( $\mathrm{E}$ and C), polyphenols or carotenoids which can be taken from diet as a main source or supplement in other conditions $(68,69)$. Both endogenous and exogenous antioxidant system work synergistically to maintain the cellular redox homeostasis.

Despite the fact that in vitro studies have highlighted the cytoprotective effect of dietary antioxidant constituents like polyphenols or carotenoids against oxidative stress or cell death, they can also display prooxidant activity, such as a number of polyphenols known by their antioxidant activity like catechin, epicatechin and quercetin, in a high concentration or in the presence of metal ions (70-72). The strong reducing power of antioxidants may affect the metal ions e.g., $\mathrm{Cu}^{2+}, \mathrm{Fe}^{3+}$, increasing their ability to form hydroxyl radicals in high concentrations through Fenton reaction from peroxides $(73,74)$.

In this regard, several studies concluded that polyphenols in higher concentrations then serve as prooxidants $(75,76)$, e.g., quercetin at higher concentrations $(>50 \mu \mathrm{M})$ can initiate ROS generation especially $\mathrm{O}_{2}{ }^{-}$; and in another study, it was observed to decrease cell viability, and TAC (77). Flavonoids such as fisetin were also investigated and found to cause cytotoxicity and apoptosis at higher concentration (50-250 $\mu \mathrm{M})$, while at lower concentration $(10-25 \mu \mathrm{M})$, they have protected rat $\mathrm{H} 4 \mathrm{IIE}$ cells from $\mathrm{H}_{2} \mathrm{O}_{2}$ induced cytotoxicity (71). Flavonoids also have the ability to generate ROS at higher concentrations via autoxidation e.g., myricetin $(78,79)$. Antioxidant phenolics, have free radical scavenging activity, they give rise to a relatively stable phenoxyl radical, due to delocalization of the unpaired electrons on the aromatic ring (80). However, these stable phenoxyl radicals can induce cellular damage through DNA oxidation, resulting in mutagenesis (75). The chelating power of phenolics may also influence their prooxidant activities, in vitro. The $\mathrm{pH}$ of the medium is also found to affect redox abilities of phenolic compounds, so at physiological $\mathrm{pH}(\mathrm{pH}$ 7.4), chelating activity may be affected, certain phenolics have displayed prooxidant activity, while at lower $\mathrm{pH}$ values, the antioxidant activity may prevail $(72,81)$.

$\mathrm{N}$-acetyl-L-cysteine (NAC) was used as exogenous antioxidant to investigate the role of ROS in tumor processes in animal models, and was found to cause impaired p53-null lymphoma and lung cancer growth through prevention of DNA oxidation and subsequent mutagenic events (82). However other studies suggested that NAC promotes tumor imitation and metastasis in mouse models of melanoma and lung cancer (83-85). Another research study reported that NAC increases melanoma metastasis in vivo through small guanosinetriphosphatase activation (86). Moreover, in a study on pancreatic ductal adenocarcinomas (PDAC) treated with NAC, the microRNA 135a and microRNA 135b (miR-135a and miR-135b) (a class of small endogenous non-protein coding RNAs capable of altering the expression of target genes and has a role in inhibiting invasion of cancer cell), 
were shown to decline (87). Like NAC, vitamin E has a role in lung cancer and melanoma initiation and progression $(83,84)$. A very large trial with selenium and vitamin E comprising 35,533 men from 427 different study sites found no reduction in prostate cancer risk in healthy individuals taking either selenium or vitamin E (88). In a randomized double-blind, placebo-controlled trial of AMATERASU, analysis was performed for 417 postoperative patients at stage I to stage III digestive tract cancer from the esophagus to the rectum, to whom a dose of 2,000 IU/day vitamin D3 was administered. Programmed death-ligand 1 (PDL1) as an anticancer immunity counter expression of cancer cells, was found to be upregulated. PD-L1 was measured through ELISA, divided into five quintiles; and vit D supplementation was found to significantly reduce the risk of relapses and death to approximately $30 \%$ of the highest quantile of serum PD-L1 (89).

In another a study with Finnish male smokers being given alpha-tocopherol and beta-carotene (ATBC trial), a higher lung cancer rate was observed in the treatment group (90,91). A larger trial composed of men and women with risk of lung cancer were given beta-carotene and retinol, and the trial was stopped due to high incidence of mortality in antioxidant treatment group. Another study observed no significant results when beta-carotene was administered to healthy women (92). Carotenoids were also found to increase mortality in breast cancer patients (93). Moreover, the correlation between increased risk of lung cancer and beta-carotene and vitamin $\mathrm{A}$ intake has drawn wide attention to the possible role of antioxidants in cancer progression (94). Furthermore, fucoxanthin (carotenoid organic pigment) also acts as prooxidant at higher concentrations increasing cellular ROS and extracellular signal regulated kinase (ERK) $1 / 2$ and p38 MAPK protein phosphorylation in murine hepatic BNL CL.2 cells, while in lower concentration, it functioned as antioxidant (95). Lycopene as a carotenoid was used in ovarian cancer study and resulted in downregulation of signal transduction of transcription factor STAT 3 which propagates tumorigenesis and mutation with deregulated cell apoptosis (95).

Vitamin C supplements in combined treatment with doxorubicin have shown to increase its activity in breast cancer (96). However, a high dose of vitamin $\mathrm{C}$ has been observed to function as ROS generator inducing the cell death of KRAS- and BRAF-mutant colon cancer cells (97). Another study showed that Vitamin C can be autoxidized to dehydroascorbate (DHA) increasing cellular oxidative stress (98). However, it is suggested that at its physiological doses, vitamin $\mathrm{C}$ antioxidant activities outweigh its prooxidant ones (99). Another study reported that high doses of vitamin $\mathrm{C}$ were cytotoxic to MCF7 and MDA-MB231 cells representing luminal and basal-like breast cancer due to oxidative stress induced by high ascorbate doses and ROS accumulation with high disruption of glycolysis and ATP levels dropping. These high ascorbate concentrations inhibited TCA cycles and increased oxygen consumption (100).

Resveratrol demonstrated the ability to trigger apoptosis in tumor cells at relatively high concentrations (101). However, resveratrol was found to increase hydroxyl radical's formation in presence of copper ion, having prooxidant activity $(102,103)$. Another study found that resveratrol effectively enhanced $\mathrm{Nk}$ cells, which is a trending approach in cancer treatment, and also increased interferon gamma (IFN- $\gamma$ ) levels along with interleukin-2 (IL-2). Additionally, NK cellular activity was boosted in both human and mouse whole blood upon resveratrol introduction (104). A number of flavonoids was further investigated for their effect on colon cancer cell lines. Naringenin, catechin and epicatechin were introduced with concentration range 5 and $25 \mu \mathrm{M}$; which resulted in decreasing mitochondrial metabolic activity, inhibiting protein kinase $\mathrm{C}$ (PKC) signaling pathway, and increasing ROS generation which subsequently induces ROS mediated apoptosis. This intracellular ROS mediated apoptosis is revealed to be concomitant with increased caspase activity (105).

Campesterol, a plant secondary metabolite steroid with antioxidant properties, was investigated in human ovarian cancer cell lines. It resulted in impaired ROS production and mitochondrial function. In a dose dependent manner, both ER stress sensor proteins expression and ROS generation were increased, as well as inhibition of cell cycle progression through PCNA and PI3K/MAPK signal pathways. Campesterol synergistically increased the activity of chemotherapeutic agents as cisplatin and paclitaxel (106). This correlation between antioxidants and ROS mediated cellular apoptosis is illustrated in Figure 2.

In diabetic patients, it has been found that multiple cancers development like breast, liver and colon cancer, are of high incidence (107). Many clinical trials have suggested that supplementation should be avoided for people with high risk of developing cancer (108). The antidiabetic drugs used to modulate glucose metabolism, which will have long term effects on diabetic patients, also affect the insulinlike growth factor-1 axis or other factors associated with cancer initiation and progression (109). A common class 


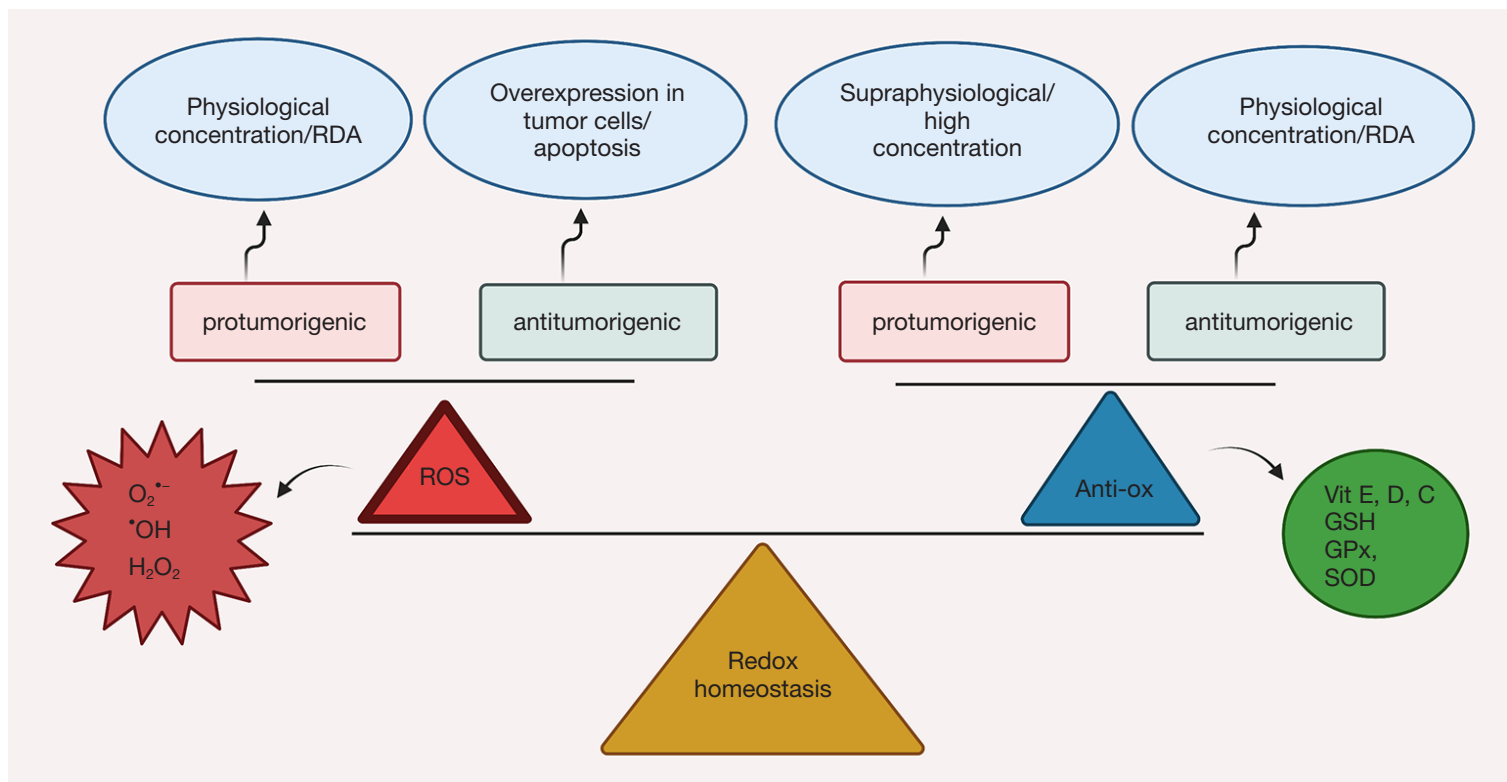

Figure 2 The link between antioxidants (exogenous or endogenous) and reactive oxygen species (ROS) as a counter force for each other into keeping redox homeostasis; both species act either antitumorigenic or protumorigenic depending on their physiological concentration/ dosing system. Recommended dietary allowance (RDA) and anti-ox denote the recommended dietary allowance and antioxidant respectively.

of antidiabetics, dipeptidyl peptidase-4 inhibitors (DPP4i), saxagliptin and sitagliptin were investigated, along with the antioxidant, antineuropathic $\alpha$-lipoic acid (ALA) for possible association with cancer incidence. No clinical evidence was found to support that DPP-4i drugs either alone or combined with other drugs, increases the risk for cancers (110). However, ALA is proven to induce prolonged activation of the nuclear factor E2-related factor 2 (NRF2) (111), which eventually enhances cancer cells invasive capacity and mobility, and accelerates tumor metastasis; although it does not increase the incidence of cancer. As a consequence of the mentioned intricate effects, antioxidants should be administered with caution to cancer patients.

\section{Conclusions}

There has been a change in the perception of ROS and antioxidants over time; as ROS have been considered as toxic molecules and been highlighted once again for their cellular signaling role, however the role of ROS in cancer progression should be extensively investigated as it may lead to development of therapeutic modalities for treatment of malignancies. Additionally, while antioxidants were thought to be exclusively beneficial, however in high doses they have been shown to contribute to tumor progression. ROS management strategies for cancer cases were trialed by using antioxidant therapy, yet with the failure of antioxidant trials as cancer therapy, a need has emerged for alternative therapies. The balance between prooxidant and antioxidant is vital for the healthy biological system, and the majority of chemotherapy disrupts the redox balance not only in cancer cells, but also in normal ones which activates adaptive responses, so when developing approaches for cancer treatment based on ROS accumulation, the antioxidant pathways that are selectively used by cancer cell must be taken into consideration.

\section{Acknowledgments}

Funding: None.

\section{Footnote}

Reporting Checklist: The authors have completed the Narrative Review reporting checklist. Available at https:// dx.doi.org/10.21037/tcr-21-629

Conflicts of Interest: Both authors have completed the ICMJE uniform disclosure form (available at https://dx.doi. 
org/10.21037/tcr-21-629). The authors have no conflicts of interest to declare.

Ethical Statement: The authors are accountable for all aspects of the work in ensuring that questions related to the accuracy or integrity of any part of the work are appropriately investigated and resolved.

Open Access Statement: This is an Open Access article distributed in accordance with the Creative Commons Attribution-NonCommercial-NoDerivs 4.0 International License (CC BY-NC-ND 4.0), which permits the noncommercial replication and distribution of the article with the strict proviso that no changes or edits are made and the original work is properly cited (including links to both the formal publication through the relevant DOI and the license). See: https://creativecommons.org/licenses/by-nc-nd/4.0/.

\section{References}

1. Harris IS, DeNicola GM. The Complex Interplay between Antioxidants and ROS in Cancer. Trends Cell Biol 2020;30:440-51.

2. St Clair DK, Wan XS, Oberley TD, et al. Suppression of radiation-induced neoplastic transformation by overexpression of mitochondrial superoxide dismutase. Mol Carcinog 1992;6:238-42.

3. Safford SE, Oberley TD, Urano M, et al. Suppression of fibrosarcoma metastasis by elevated expression of manganese superoxide dismutase. Cancer Res 1994;54:4261-5.

4. Sena LA, Chandel NS. Physiological roles of mitochondrial reactive oxygen species. Mol Cell 2012;48:158-67.

5. Marengo B, Nitti M, Furfaro AL, et al. Redox Homeostasis and Cellular Antioxidant Systems: Crucial Players in Cancer Growth and Therapy. Oxid Med Cell Longev 2016;2016:6235641.

6. Forman HJ, Davies MJ, Krämer AC, et al. Protein cysteine oxidation in redox signaling: Caveats on sulfenic acid detection and quantification. Arch Biochem Biophys 2017;617:26-37.

7. Cross CE, Halliwell B, Borish ET, et al. Oxygen radicals and human disease. Ann Intern Med 1987;107:526-45.

8. Holmström KM, Finkel T. Cellular mechanisms and physiological consequences of redox-dependent signalling. Nat Rev Mol Cell Biol 2014;15:411-21.

9. Espinosa-Diez C, Miguel V, Mennerich D, et al. Antioxidant responses and cellular adjustments to oxidative stress. Redox Biol 2015;6:183-97.

10. Halvey PJ, Watson WH, Hansen JM, et al. Compartmental oxidation of thiol-disulphide redox couples during epidermal growth factor signalling. Biochem J 2005;386:215-9.

11. Morgan MJ, Liu ZG. Crosstalk of reactive oxygen species and NF- $\kappa$ B signaling. Cell Res 2011;21:103-15.

12. Vollaard NB, Shearman JP, Cooper CE. Exercise-induced oxidative stress:myths, realities and physiological relevance. Sports Med 2005;35:1045-62.

13. Riley PA. Free radicals in biology: oxidative stress and the effects of ionizing radiation. Int J Radiat Biol 1994;65:27-33.

14. Chaiswing L, St Clair WH, St Clair DK. Redox Paradox: A Novel Approach to Therapeutics-Resistant Cancer. Antioxid Redox Signal 2018;29:1237-72.

15. Hercberg S, Galan P, Preziosi P, et al. The potential role of antioxidant vitamins in preventing cardiovascular diseases and cancers. Nutrition 1998;14:513-20.

16. Zhong GC, Pu JY, Wu YL, et al. Total Antioxidant Capacity and Pancreatic Cancer Incidence and Mortality in the Prostate, Lung, Colorectal, and Ovarian Cancer Screening Trial. Cancer Epidemiol Biomarkers Prev 2020;29:1019-28.

17. Aggarwal V, Tuli HS, Varol A, et al. Role of Reactive Oxygen Species in Cancer Progression: Molecular Mechanisms and Recent Advancements. Biomolecules 2019;9:735.

18. Hansen JM, Go YM, Jones DP. Nuclear and mitochondrial compartmentation of oxidative stress and redox signaling. Annu Rev Pharmacol Toxicol 2006;46:215-34.

19. Chitty JL, Filipe EC, Lucas MC, et al. Recent advances in understanding the complexities of metastasis. F1000Res 2018.

20. Trachootham D, Alexandre J, Huang P. Targeting cancer cells by ROS-mediated mechanisms: a radical therapeutic approach? Nat Rev Drug Discov 2009;8:579-91.

21. Trachootham D, Zhou Y, Zhang H, et al. Selective killing of oncogenically transformed cells through a ROSmediated mechanism by beta-phenylethyl isothiocyanate. Cancer Cell 2006;10:241-52.

22. Schieber M, Chandel NS. ROS function in redox signaling and oxidative stress. Curr Biol 2014;24:R453-62.

23. Finkel T. Signal transduction by reactive oxygen species. J Cell Biol 2011;194:7-15.

24. Reczek CR, Chandel NS. ROS-dependent signal transduction. Curr Opin Cell Biol 2015;33:8-13.

25. Brand MD. Mitochondrial generation of superoxide and hydrogen peroxide as the source of mitochondrial redox signaling. Free Radic Biol Med 2016;100:14-31. 
26. D'Autréaux B, Toledano MB. ROS as signalling molecules: mechanisms that generate specificity in ROS homeostasis. Nat Rev Mol Cell Biol 2007;8:813-24.

27. Goncalves RL, Quinlan CL, Perevoshchikova IV, et al. Sites of superoxide and hydrogen peroxide production by muscle mitochondria assessed ex vivo under conditions mimicking rest and exercise. J Biol Chem 2015;290:209-27.

28. Brewer TF, Garcia FJ, Onak CS, et al. Chemical approaches to discovery and study of sources and targets of hydrogen peroxide redox signaling through NADPH oxidase proteins. Annu Rev Biochem 2015;84:765-90.

29. Murphy MP. How mitochondria produce reactive oxygen species. Biochem J 2009;417:1-13.

30. Little AC, Sulovari A, Danyal K, et al. Paradoxical roles of dual oxidases in cancer biology. Free Radic Biol Med 2017;110:117-32.

31. Chen Y, Azad MB, Gibson SB. Superoxide is the major reactive oxygen species regulating autophagy. Cell Death Differ 2009;16:1040-52.

32. Brennan JP, Bardswell SC, Burgoyne JR, et al. Oxidantinduced activation of type I protein kinase A is mediated by RI subunit interprotein disulfide bond formation. J Biol Chem 2006;281:21827-36.

33. Katz M, Amit I, Yarden Y. Regulation of MAPKs by growth factors and receptor tyrosine kinases. Biochim Biophys Acta 2007;1773:1161-76.

34. Cantley LC. The phosphoinositide 3-kinase pathway. Science 2002;296:1655-7.

35. Los M, Maddika S, Erb B, et al. Switching Akt: from survival signaling to deadly response. Bioessays 2009;31:492-5.

36. Ogrunc M. Reactive oxygen species: The good, the bad, and the enigma. Mol Cell Oncol 2014;1:e964033.

37. Kröller-Schön S, Steven S, Kossmann S, et al. Molecular mechanisms of the crosstalk between mitochondria and NADPH oxidase through reactive oxygen species-studies in white blood cells and in animal models. Antioxid Redox Signal 2014;20:247-66.

38. Mochizuki T, Furuta S, Mitsushita J, et al. Inhibition of NADPH oxidase 4 activates apoptosis via the AKT/ apoptosis signal-regulating kinase 1 pathway in pancreatic cancer PANC-1 cells. Oncogene 2006;25:3699-707.

39. Ye J, Fan J, Venneti S, et al. Serine catabolism regulates mitochondrial redox control during hypoxia. Cancer Discov 2014;4:1406-17.

40. Harris AL. Hypoxia--a key regulatory factor in tumour growth. Nat Rev Cancer 2002;2:38-47.

41. Aykin-Burns N, Ahmad IM, Zhu Y, et al. Increased levels of superoxide and $\mathrm{H} 2 \mathrm{O} 2$ mediate the differential susceptibility of cancer cells versus normal cells to glucose deprivation. Biochem J 2009;418:29-37.

42. Semenza GL. Hypoxia-inducible factors in physiology and medicine. Cell 2012;148:399-408.

43. Finkel T, Serrano M, Blasco MA. The common biology of cancer and ageing. Nature 2007;448:767-74.

44. Horak P, Crawford AR, Vadysirisack DD, et al. Negative feedback control of HIF-1 through REDD1-regulated ROS suppresses tumorigenesis. Proc Natl Acad Sci U S A 2010;107:4675-80.

45. Valko M, Leibfritz D, Moncol J, et al. Free radicals and antioxidants in normal physiological functions and human disease. Int J Biochem Cell Biol 2007;39:44-84.

46. DeNicola GM, Karreth FA, Humpton TJ, et al. Oncogene-induced Nrf2 transcription promotes ROS detoxification and tumorigenesis. Nature 2011;475:106-9.

47. Winterbourn CC. Biological chemistry of superoxide radicals. Chem Texts 2020. doi: 10.1007/s40828-019-0101-8

48. Tsuchiya Y, Peak-Chew SY, Newell C, et al. Protein CoAlation: a redox-regulated protein modification by coenzyme A in mammalian cells. Biochem J 2017;474:2489-508.

49. Miki H, Funato Y. Regulation of intracellular signalling through cysteine oxidation by reactive oxygen species. J Biochem 2012;151:255-61.

50. Hoshi T, Heinemann S. Regulation of cell function by methionine oxidation and reduction. J Physiol 2001;531:1-11.

51. Lee JW, Helmann JD. The PerR transcription factor senses $\mathrm{H} 2 \mathrm{O} 2$ by metal-catalysed histidine oxidation. Nature 2006;440:363-7.

52. Veal EA, Day AM, Morgan BA. Hydrogen peroxide sensing and signaling. Mol Cell 2007;26:1-14.

53. Kruiswijk F, Labuschagne CF, Vousden KH. p53 in survival, death and metabolic health: a lifeguard with a licence to kill. Nat Rev Mol Cell Biol 2015;16:393-405.

54. Levine AJ, Oren M. The first 30 years of p53: growing ever more complex. Nat Rev Cancer 2009;9:749-58.

55. Khromova NV, Kopnin PB, Stepanova EV, et al. p53 hotspot mutants increase tumor vascularization via ROSmediated activation of the HIF1/NEGF-A pathway. Cancer Lett 2009;276:143-51.

56. Wang A, Jiang H, Liu Y, et al. Rhein induces liver cancer cells apoptosis via activating ROS-dependent JNK/Jun/ caspase-3 signaling pathway. J Cancer 2020;11:500-7.

57. Geng J, Yuan X, Wei M, et al. The diverse role of TIGAR in cellular homeostasis and cancer. Free Radic Res 2018;52:1240-9. 
58. Longley DB, Harkin DP, Johnston PG. 5-fluorouracil: mechanisms of action and clinical strategies. Nat Rev Cancer 2003;3:330-8.

59. Jiang L, Kon N, Li T, et al. Ferroptosis as a p53-mediated activity during tumour suppression. Nature 2015;520:57-62.

60. Kelly KM, Jacobson JS, Kennedy DD, et al. Use of unconventional therapies by children with cancer at an urban medical center. J Pediatr Hematol Oncol 2000;22:412-6.

61. Burstein HJ, Gelber S, Guadagnoli E, et al. Use of alternative medicine by women with early-stage breast cancer. N Engl J Med 1999;340:1733-9.

62. Ray G, Batra S, Shukla NK, et al. Lipid peroxidation, free radical production and antioxidant status in breast cancer. Breast Cancer Res Treat 2000;59:163-70.

63. Prasad KN, Cole WC, Kumar B, et al. Scientific rationale for using high-dose multiple micronutrients as an adjunct to standard and experimental cancer therapies. J Am Coll Nutr 2001;20:450S-75S.

64. Conklin KA. Dietary antioxidants during cancer chemotherapy: impact on chemotherapeutic effectiveness and development of side effects. Nutr Cancer 2000;37:1-18.

65. Lamson DW, Brignall MS. Antioxidants in cancer therapy; their actions and interactions with oncologic therapies. Altern Med Rev 1999;4:304-29.

66. Prasad KN, Kumar A, Kochupillai V, et al. High doses of multiple antioxidant vitamins: essential ingredients in improving the efficacy of standard cancer therapy. J Am Coll Nutr 1999;18:13-25.

67. Ladas EJ, Jacobson JS, Kennedy DD, et al. Antioxidants and cancer therapy: a systematic review. J Clin Oncol 2004;22:517-28.

68. Ratnam DV, Ankola DD, Bhardwaj V, et al. Role of antioxidants in prophylaxis and therapy: A pharmaceutical perspective. J Control Release 2006;113:189-207.

69. Andre CM, Larondelle Y, Evers D. Dietary antioxidants and oxidative stress from a human and plant perspective: a review. Curr Nutr Food Sci 2010;6:2-12.

70. Azam S, Hadi N, Khan NU, et al. Prooxidant property of green tea polyphenols epicatechin and epigallocatechin-3gallate: implications for anticancer properties. Toxicol In Vitro 2004;18:555-61.

71. Wätjen W, Michels G, Steffan B, et al. Low concentrations of flavonoids are protective in rat H4IIE cells whereas high concentrations cause DNA damage and apoptosis. J Nutr 2005;135:525-31.

72. Decker EA. Phenolics: prooxidants or antioxidants? Nutr Rev 1997;55:396-8.
73. Bouayed J. Polyphenols: a potential new strategy for the prevention and treatment of anxiety and depression. Curr Nutr Food Sci 2010;6:13-8.

74. Jacques DE, Jean-Louis BE, Dominique BR. Radicaux libres et stress oxydant: Aspects biologiques et pathologiques (broché). Lavoisier; 2007 Jan 23.

75. Galati G, O'Brien PJ. Potential toxicity of flavonoids and other dietary phenolics: significance for their chemopreventive and anticancer properties. Free Radic Biol Med 2004;37:287-303.

76. Sergediene E, Jönsson K, Szymusiak H, et al. Prooxidant toxicity of polyphenolic antioxidants to HL-60 cells: description of quantitative structure-activity relationships. FEBS Lett 1999;462:392-6.

77. Robaszkiewicz A, Balcerczyk A, Bartosz G. Antioxidative and prooxidative effects of quercetin on A549 cells. Cell Biol Int 2007;31:1245-50.

78. Metodiewa D, Jaiswal AK, Cenas N, et al. Quercetin may act as a cytotoxic prooxidant after its metabolic activation to semiquinone and quinoidal product. Free Radic Biol Med 1999;26:107-16.

79. Gaspar J, Rodrigues A, Laires A, et al. On the mechanisms of genotoxicity and metabolism of quercetin. Mutagenesis 1994;9:445-9.

80. Rice-Evans CA, Miller NJ, Paganga G. Structureantioxidant activity relationships of flavonoids and phenolic acids. Free Radic Biol Med 1996;20:933-56.

81. Moran JF, Klucas RV, Grayer RJ, et al. Complexes of iron with phenolic compounds from soybean nodules and other legume tissues: prooxidant and antioxidant properties. Free Radic Biol Med 1997;22:861-70.

82. Sablina AA, Budanov AV, Ilyinskaya GV, et al. The antioxidant function of the p53 tumor suppressor. Nat Med 2005;11:1306-13.

83. Le Gal K, Ibrahim MX, Wiel C, et al. Antioxidants can increase melanoma metastasis in mice. Sci Transl Med 2015;7:308re8.

84. Sayin VI, Ibrahim MX, Larsson E, et al. Antioxidants accelerate lung cancer progression in mice. Sci Transl Med 2014;6:221ra15.

85. Piskounova E, Agathocleous M, Murphy MM, et al. Oxidative stress inhibits distant metastasis by human melanoma cells. Nature 2015;527:186-91.

86. Imai H, Matsuoka M, Kumagai T, et al. Lipid Peroxidation-Dependent Cell Death Regulated by GPx4 and Ferroptosis. Curr Top Microbiol Immunol 2017;403:143-70.

87. Reid MA, Wang WI, Rosales KR, et al. The B55 $\alpha$ subunit 
of PP2A drives a p53-dependent metabolic adaptation to glutamine deprivation. Mol Cell 2013;50:200-11.

88. Zou X, Zhu Y, Park SH, et al. SIRT3-Mediated Dimerization of IDH2 Directs Cancer Cell Metabolism and Tumor Growth. Cancer Res 2017;77:3990-9.

89. Morita M, Okuyama M, Akutsu T, et al. Vitamin D Supplementation Regulates Postoperative Serum Levels of PD-L1 in Patients with Digestive Tract Cancer and Improves Survivals in the Highest Quintile of PD-L1: A Post Hoc Analysis of the AMATERASU Randomized Controlled Trial. Nutrients 2021;13:1987.

90. Albanes D, Heinonen OP, Taylor PR, et al. AlphaTocopherol and beta-carotene supplements and lung cancer incidence in the alpha-tocopherol, beta-carotene cancer prevention study: effects of base-line characteristics and study compliance. J Natl Cancer Inst 1996;88:1560-70.

91. Alpha-Tocopherol, Beta Carotene Cancer Prevention Study Group. The effect of vitamin E and beta carotene on the incidence of lung cancer and other cancers in male smokers. N Engl J Med 1994;330:1029-35.

92. Lee IM, Cook NR, Manson JE, et al. Beta-carotene supplementation and incidence of cancer and cardiovascular disease: the Women's Health Study. J Natl Cancer Inst 1999;91:2102-6.

93. Greenlee H, Kwan ML, Kushi LH, et al. Antioxidant supplement use after breast cancer diagnosis and mortality in the Life After Cancer Epidemiology (LACE) cohort. Cancer 2012;118:2048-58.

94. Omenn GS, Goodman GE, Thornquist MD, et al. Effects of a combination of beta carotene and vitamin A on lung cancer and cardiovascular disease. N Engl J Med 1996;334:1150-5.

95. Sahin K, Yenice E, Tuzcu M, et al. Lycopene Protects Against Spontaneous Ovarian Cancer Formation in Laying Hens. J Cancer Prev 2018;23:25-36.

96. Guerriero E, Sorice A, Capone F, et al. Vitamin C effect on mitoxantrone-induced cytotoxicity in human breast cancer cell lines. PLoS One 2014;9:e115287.

97. Yun J, Mullarky E, Lu C, et al. Vitamin C selectively kills KRAS and BRAF mutant colorectal cancer cells by targeting GAPDH. Science 2015;350:1391-6.

98. Schoenfeld JD, Sibenaller ZA, Mapuskar KA, et al. O2•and H2O2-Mediated Disruption of Fe Metabolism Causes the Differential Susceptibility of NSCLC and GBM Cancer Cells to Pharmacological Ascorbate. Cancer Cell 2017;31:487-500.e8.

99. Podmore ID, Griffiths HR, Herbert KE, et al. Vitamin C exhibits pro-oxidant properties. Nature 1998;392:559.

100. Ghanem A, Melzer AM, Zaal E, et al. Ascorbate kills breast cancer cells by rewiring metabolism via redox imbalance and energy crisis. Free Radic Biol Med 2021;163:196-209.

101. Clément MV, Hirpara JL, Chawdhury SH, et al. Chemopreventive agent resveratrol, a natural product derived from grapes, triggers CD95 signaling-dependent apoptosis in human tumor cells. Blood 1998;92:996-1002.

102. Khan HY, Zubair H, Faisal M, et al. Plant polyphenol induced cell death in human cancer cells involves mobilization of intracellular copper ions and reactive oxygen species generation: a mechanism for cancer chemopreventive action. Mol Nutr Food Res 2014;58:437-46.

103. Ahmad A, Syed FA, Singh S, et al. Prooxidant activity of resveratrol in the presence of copper ions: mutagenicity in plasmid DNA. Toxicol Lett 2005;159:1-12.

104.Lee Y, Shin H, Kim J. In vivo Anti-Cancer Effects of Resveratrol Mediated by NK Cell Activation. J Innate Immun 2021;13:94-106.

105. Dükel M, Tavsan Z, Kayali HA. Flavonoids regulate cell death-related cellular signaling via ROS in human colon cancer cells. Process Biochem 2021;101:11-25.

106. Bae H, Park S, Yang C, et al. Disruption of Endoplasmic Reticulum and ROS Production in Human Ovarian Cancer by Campesterol. Antioxidants (Basel) 2021;10:379.

107. Giovannucci E, Harlan DM, Archer MC, et al. Diabetes and cancer: a consensus report. CA Cancer J Clin 2010;60:207-21.

108. Chandel NS, Tuveson DA. The promise and perils of antioxidants for cancer patients. N Engl J Med 2014;371:177-8.

109. Smith U, Gale EA. Does diabetes therapy influence the risk of cancer? Diabetologia 2009;52:1699-708.

110. Wang H, Liu X, Long M, et al. NRF2 activation by antioxidant antidiabetic agents accelerates tumor metastasis. Sci Transl Med 2016;8:334ra51.

111. Suh JH, Shenvi SV, Dixon BM, et al. Decline in transcriptional activity of $\mathrm{Nrf} 2$ causes age-related loss of glutathione synthesis, which is reversible with lipoic acid. Proc Natl Acad Sci U S A 2004;101:3381-6.

Cite this article as: Bekhet $\mathrm{OH}$, Eid ME. The interplay between reactive oxygen species and antioxidants in cancer progression and therapy: a narrative review. Transl Cancer Res 2021;10(9):4196-4206. doi: 10.21037/tcr-21-629 